\title{
The Application of Ethylene Propylene Rubber Production Technology Research
}

\author{
Lijun Qi \\ Weifang University of Science and Technology \\ Shou Guang, 262700, China
}

\begin{abstract}
This paper first introduces the chemical structure of ethylene-propylene rubber (EPR) composition and performance. And then expounds the production technology of ethylene propylene rubber, of which mainly is the story of metallocene catalysis technology and the metallocene catalysis technology. Finally, the application and prospect of ethylene propylene rubber made a brief introduction.
\end{abstract}

Keywords-Ethylene propylene rubber; Production technology; application; current situation of the development of

\section{INTRODUCTION}

Ethylene propylene rubber in the international market has excess capacity, and insufficient in our country, the reliance on the global market is very large. Therefore, overcapacity and manufacturers will further expand the occupation of the market, relying on advanced technology and complete product brands, low production cost, and good after-sales service, etc., at a relatively low price to the Chinese practice dumping, cause huge impact to the domestic market, influence the development of ethylene-propylene rubber in China in the future.

\section{CHEMICAL STRUCTURE AND ITS PERFORMANCE}

\section{A. Chemical composition of}

Ethylene propylene rubber series in a single olefin ethylene, propylene copolymer as binary ethylene-propylene rubber; with ethylene, propylene and a small amount of the conjugate dienes as monomer copolymerization and produce epic. Ethylene propylene rubber molecules on the main chain, ethylene and propylene monomer are arranged without rules, lost the regularity of the structure of polyethylene or polypropylene, becoming the elastomer, due to the exam alkadiene is located in a side chain, so the ends can not only use sulfur vulcanization, while maintaining the dual properties of ethylene propylene rubber.

\section{B. The main performance}

\section{1) Low density and high filling ability}

Rubber ethylene-propylene rubber is low density. Its density is 0.87 . Combined with the filling agent, can be added a large number of oil charge and thus can reduce the cost of rubber products, made up for the shortcoming of ethylene propylene rubber raw rubber prices high, for halls, value of ethylene propylene rubber, high physical and mechanical properties after filling to reduce much.

\section{2) Aging resistance}

Ethylene propylene rubber has excellent weather resistance, ozone resistance, heat resistance, acid and alkali resistance, water vapor, color stability, electronic, oily and normal temperature liquid filling. Ethylene propylene rubber products under 120 can be used for a long time, under the 150-200 can be temporary or intermittent use. Join the suitable stabilizer can increase the temperature. With peroxide cross linked rpm can be used in more stringent conditions. Pm in 50 PPHM, drawing $30 \%$ of the ozone concentration condition, can reach more than $150 \mathrm{~h}$ not cracked.

\section{3) Corrosion resistance}

Due to the lack of polarity ethylene propylene rubber low unsaturation, polarity of various chemicals such as alcohol, acid, alkali, oxidant, refrigerant, detergents, animal and plant oil, ketone and fat has good resistance to patience; But the fat and aromatic solvents (such as 
gasoline, benzene, etc.) and poor stability of mineral oil. Under the action of concentrated acid long-term performance will decline.

\section{ETHYLENE PROPYLENE RUBBER PRODUCTION}

\section{TECHNOLOGY}

A. Aggregate all programs

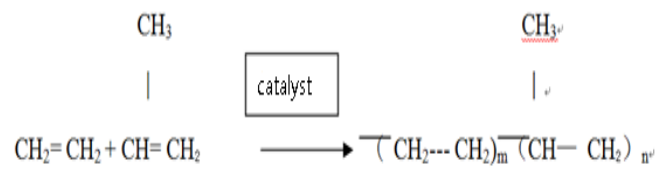

EPNI copolymer

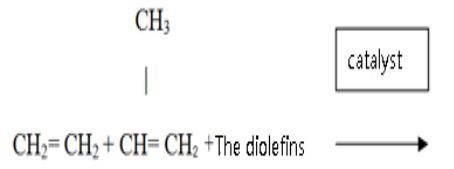

$\mathrm{CH}_{3}$

I.

$\left(\mathrm{CH}_{2} \cdots \mathrm{CH}_{2}\right)_{\mathrm{m}}-\left(\mathrm{CH}-\mathrm{CH}_{2}\right)_{\mathrm{n}}-(\text { diolefins })_{\mathrm{y}}$

EPDNiterpolymer

Figure 1. The aggregate all programs

B. Ethylene propylene rubber polymerization catalysts

\section{1) Metallocene catalysis technology}

Metallocene catalysts used in ethylene propylene rubber synthesis and realize industrialization, marked the ethylene propylene rubber synthesis technology into a new stage of development, a milestone. Metallocene catalytic ethylene-propylene copolymerization technique has the advantage of catalytic activity of high efficiency, less dosage, catalyst residue is little, don't need to rush off to deal with, can use the high temperature solution polymerization. Polymerization liquid ethylene propylene rubber in high concentration (16.4\%), high heat energy utilization, product color shallow, homogeneous polymer structure, uniform the length of the chain, bulk density is small, relatively narrow molecular weight distribution and chemical composition, especially can be adjusted by changing the structure of metallocene can accurately the composition of ethylene, propylene and dienes, control the polymer microstructure in large scale, so as to create brand new chain structure of the different USES of products. This can be binary ethylene-propylene rubber production, also can produce epic characteristics make it become the ethylene propylene rubber has the development potential of catalyst type cocatalyst is an important part of metallocene catalyst. Currently the most used cocatalyst is MAO. Because of the production of MAO, the production cost is higher, and the use of metallocene catalytic system, and to a great extent, limits the speed the development of metallocene catalyst. Therefore, in recent years, the positive progress does not use MAO cocatalyst highly active metallocene catalytic system become a hotspot in the field of research and development of domestic and foreign ethylene propylene rubber development trend.

\section{2) Not for single-site catalyst of alum}

In the history of the synthesis of ethylene-propylene elastomer, following the traditional ZieglerNatta catalyst and metallocene catalyst, the MAO single center (also known as single active center) catalyst has been applied in ethylene propylene rubber synthesis, and a breakthrough. Competition for a new generation of non main single-point catalysts including nickel, palladium catalyst, iron and cobalt catalysts such as type of single point of the catalyst. Some of this kind of catalyst performance have reached or exceed the metallocene catalyst, some of alum single-point catalyst have been used in polyolefin production. Holland DSM company at the end of 2008 by Nova chemical company of alum catalyst for single point in the Dutch Galen set of epdm device to produce new type of elastomer products to ACE, early in 2009 the first batch of special epdm Certance products available, including a class containing high selectivity vinyl norbornadiene ene (VNB) as a new type of the third monomer epdm in recent years, in addition to the current commonly used b fork norbornadiene ene (ENB), double loop pentadiene (DCPD) and 1, 4 - diallyl (1, $4 \mathrm{HD})$ as the third monomer, such as some other new olefin monomer like 5 - vinyl 2 borneol ene (VNB), 1, 7 symplectic diene, 7 - methyl 1-6 - symplectic diene also 
gradually into the ethylene propylene rubber polymer. These alkenes participation as a third or fourth monomer copolymerization reaction of ethylene and propylene, were such as ethylene octave binary copolymer (EOC), ethylene, propylene VNB terpolymer, ethylene, propylene, ENBVNB quaternary copolymer such as new products, which gives ethylene-propylene elastomer new functions, makes the performance of ethylene propylene rubber is more specialized, more WanShanHua.

\section{THE APPLICATION AND PROSPECT OF ETHYLENE} PROPYLENE RUBBER.

\section{A. The application of ethylene propylene} rubber

Because of the main chain of the ethylene propylene rubber molecules for saturated structure presents excellent weather resistance, ozone resistance, electrical insulation, low compression permanent deformation, high strength and high elongation performance, such as precious its application is very extensive, consumption increases year by year. According to the different series of ethylene propylene rubber and the characteristics of the molecular structure, ethylene propylene rubber application types with common type, mixed type, fast curing, easy processing and alkadiene rubber with different applications, such as the type. From the actual application situation analysis, ethylene propylene rubber has been extensively used in the tire.

\section{1) The car industry}

Ethylene propylene rubber are the biggest in the automotive industry, mainly used in automotive sealing strip, radiator hose, the sheath of the spark plug, air conditioning hose, rubber gasket, rubber hose, etc. In the automotive sealing strip, the main use of EPDM elastic, ozone resistance, weather resistance and other characteristics, its ENB of EPDM rubber has become the main body of car seal materials, domestic raw rubber consumption has more than 10000 tons, but due to the variety, its half still rely on imports. Because of EPDM/PP thermoplastic EPDM rubber high strength, good flexibility, high gloss coating, the characteristics of easy recycling at home and abroad, car bumper and car dashboard have been as the dominant material in the production.

\section{2) The construction industry}

Because of ethylene-propylene rubber has excellent water resistance, heat-resistant, cold resistance and weatherability and easy construction etc., thus ethylene-propylene rubber in the construction industry is mainly used for plastic playground, waterproofing materials, building doors and Windows sealing strip, glass curtain wall sealing, health equipment and pipe seals, etc. Ethylene propylene rubber consumption in the building industry's largest number of plastic playground and waterproofing materials, in terms of domestic consumption has accounted for $26 \%$ of the total amount of ethylene propylene rubber - 28\% [8]. With EPDM production of waterproofing materials has been gradually replacing other materials (such as CMS) production of waterproofing materials, especially used in underground construction waterproofing materials.

\section{B. Development prospect of ethylene-propylene rubber}

In recent years, with the rapid development of China's automobile industry, construction and other industries, the demand for ethylene propylene rubber increased significantly. In 2005, apparent consumption of Chinese ethylene propylene rubber is $92300 \mathrm{~T}, 2007$, 129800 T, further increased to 189700 t, 2009, up 33.03\% from a year earlier. Ethylene propylene rubber in our country is mainly used for automobile components, waterproofing materials, wire and cable, oil modifier and polyolefin modified agents, etc. In 2009, the consumption structure of ethylene propylene rubber in our country as: automobile industry on the demand of ethylene propylene rubber accounts for about $42.11 \%$ of the total demand, waterproofing materials account for about $9.47 \%$, wire and cable accounts for about $8.95 \%$, oil additives accounted for about $9.47 \%$, polymer modified accounted for about $12.11 \%$, plastic runway $(12.63 \%)$, other aspects 
about $5.26 \%$. In the next few years, along with our country automobile industry and urban basic construction, the continuous development of rail transit construction, the demand for ethylene propylene rubber will continue to increase. By 2014, total demand of ethylene propylene rubber in China will reach about $240000 \mathrm{t}$.

\section{CONCLUSION}

As long as more information about its features and performance of ethylene propylene rubber, make full use of the unique performance of ethylene propylene rubber, to better solve the problem of waste rubber recycling utilization, reduce the price of raw rubber of ethylene propylene rubber, ethylene propylene rubber applications and will make greater development demand.

\section{REFERENCES}

[1] Dongming Bai. Ethylene propylene rubber technology progress [J]. Chemical engineers, 2010, (6): 41-48.

[2] Guilun Wang, LongJiangZhang. The application of metallocene catalyst in ethylene propylene rubber [J]. Journal of the synthetic rubber industry, 2003, 26 (5): 324-327.
[3] Rongzhong Yin. Phenolic resin and its application [M]. Beijing: Chemical industry press, 1994, 1-97.

[4] Zhilu Wang. Synthetic adhesive and its new development [M]. Beijing: Science press, 1994, 14-25101-108.

[5] Dongwei Ma. Adhesive preparation and application [M]. Beijing: Chemical industry press, 1998.1 to $16,126-130$.

[6] Changfu Ma. Practical adhesive technology 460 q [M]. Beijing: shield Press, 1992, 23.

[7] Xuzhu Wang. The design process of a graphic designer, Beijing, China Youth publishing house, 1999.

[8] Guosheng Lin. The existence of the extraction of Chinese characters symbolic value and competitive advantage, 2001.8.

[9] Xigang Zhao. "modern graphic design and traditional design" (" the decoration ", 2003, 4.

[10] Ruilin Chen. "The history of Chinese modern art design," human science and technology publishing house.

[11] Yanzu Li, "the history of visual communication design and aesthetics", the Chinese people's university press, 2000.

[12] Yucheng Lu. The auspicious concept in the traditional decorative pattern and modern design, 2004.1. 